\title{
Programa de Pós-Graduação em Serviço Social da UFPA: elementos históricos e temas de pesquisa em 20 anos
}

\author{
Adriana de Azevedo Mathis \\ Universidade Federal do Pará (UFPA) \\ Joana Valente Santana \\ Universidade Federal do Pará (UFPA)
}

\author{
Max Nazareno Miranda da Silva \\ Universidade Federal do Pará (UFPA) \\ Jaqueline do Nascimento Cruz \\ Universidade Federal do Pará (UFPA)
}

Programa de Pós-Graduação em Serviço Social da UFPA: elementos históricos e temas de pesquisa em 20 anos

Resumo: Nos últimos vinte anos, muitos foram os temas de pesquisa das Dissertações de Mestrado em Serviço Social e os desafios do Programa de Pós-Graduação em Serviço Social (PPGSS) da UFPA. Este artigo, situando-se no contexto da pós-graduação do Serviço Social brasileiro, apresenta os dados temáticos de 195 dissertações do PPGSS-UFPA, no período de 1998 a 2016 e aborda a relação entre os temas pesquisados e os debates realizados pela Associação Brasileira de Ensino e Pesquisa em Serviço Social (ABEPSS), conjunto CFESS/CRESS (Conselhos Federal e Regional de Serviço Social) e os Diretórios de pesquisa no CNPq/Área do Serviço Social. O levantamento das dissertações indica o Trabalho como a temática mais recorrente, seguindo-se Formação e Espaço Socioprofissional do Serviço Social, Questão Urbana e Agrária, Política de Seguridade Social, Questões Geracionais e Movimentos Sociais, dentre outros. Palavras-chave: Programa de Pós-Graduação em Serviço Social da UFPA. Temas de pesquisa. Desafios da Pós-Graduação na Amazônia.

Graduate Program in Social Work at UFPA: historical elements and research themes over 20 years Abstract: In the last twenty years, many research themes were addressed in the Master's theses in Social Work and several challenges were faced by the Graduate Program in Social Work (PPGSS) of UFPA. This paper, written within the Brazilian context of graduate studies in Social Work, presents thematic data of 195 theses from PPGSS-UFPA, in the period from 1998 to 2016, and addresses the relationship between the study themes as well as the discussions held by the Brazilian Association of Teaching and Research in Social Work (ABEPSS), CFESS/CRESS (Federal and Regional Councils of Social Work) and the research directories in CNPq/field of Social Work. The bibliographic review of the theses indicates Work as the most frequently addressed theme, followed by Education and Training and Socio-Professional Space of Social Work, Urban and Agrarian Issues, Social Security, Generational Issues and Social Movements, among others.

Keywords: Graduate Program in Social Work at UFPA. Research Themes. Challenges faced by Graduate Studies in the Amazon. 


\section{Introdução}

O presente texto pretende indicar, nos últimos vinte anos ${ }^{1}$, os temas de pesquisa das dissertações de Mestrado em Serviço Social e os desafios do Programa de Pós-Graduação em Serviço Social da Universidade Federal do Pará (PPGSS-UFPA) no contexto da pós-graduação do Serviço Social brasileiro. Os dados coletados foram sistematizados mediante pesquisa documental em 195 dissertações. A coleta foi realizada nos documentos físicos das dissertações arquivadas na sala do PPGSS-UFPA, bem como no endereço eletrônico desse Programa, onde se encontra disponibilizada, em formato PDF, parte das dissertações defendidas.

Após catalogação dos 195 documentos, foram lidos os títulos, os resumos e as palavras-chave, como forma de apreender as linhas de pesquisa e temáticas de estudo das dissertações existentes nos arquivos do PPGSS, sistematizando-as em 10 (dez) áreas temáticas, a serem identificadas neste artigo. Nesse sentido, com base nas dissertações de Mestrado defendidas no âmbito do Programa de Pós-Graduação em Serviço Social da UFPA, objetiva-se expor os temas das pesquisas realizadas, os quais expressam a vivência desse Programa em seus 20 anos de existência. As reflexões trazidas neste artigo serão apresentadas em duas seções, seguidas das conclusões. Na primeira seção, sinaliza-se a trajetória histórica, teórica e política do PPGSS-UFPA, marcada pelo quadro de renovação do Serviço Social brasileiro mediante o processo de revisão curricular, iniciado na década de 1970, e, também, pelo processo de formação do Serviço Social brasileiro, que investe na construção de uma direção intelectual e política pautada em uma perspectiva crítica para o exercício interventivo do assistente social. Na segunda seção, merecem destaque a caracterização do PPGSS-UFPA, a identificação das principais temáticas abordadas nas dissertações de Mestrado e os desafios à pesquisa na Região Amazônica.

\section{Serviço Social brasileiro: tendências recentes da pesquisa e pós-graduação}

É consenso na literatura do Serviço Social brasileiro que as pós-graduações e as pesquisas em Serviço Social no Brasil avançaram significativamente em termos de quantidade e qualidade. A produção de conhecimento e a organização da categoria na construção das diretrizes curriculares articuladas ao Projeto ÉticoPolítico da profissão garantiram o reconhecimento desta como área de conhecimento e como profissão que luta pela defesa intransigente dos direitos humanos².

Nesse processo, a pesquisa cumpriu papel fundamental para a profissão. Registra-se o trabalho de investigação de Marilda Iamamoto e Raul de Carvalho e a tese de doutorado de José Paulo Netto, que colocam, como objeto de pesquisa, a profissão e questionam o papel desta no processo de reprodução das relações sociais, no âmbito da divisão social do trabalho (IAMAMOTO; CARVALHO, 1988; NETTO, 1996, 2001). Na sequência, a pesquisa em Serviço Social avança para o desvelamento das expressões da questão social pautando, como objeto de estudo, as mediações e as determinações constitutivas do fazer profissional, abarcando uma variedade de temas em estudo.

Em termos históricos, o avanço da pesquisa e da pós-graduação se articula, a partir da década de 1960, com o Movimento de Reconceituação latino-americano ${ }^{3}$ e, no Brasil, nas décadas de 1960 a 1980 , com o Processo de Renovação do Serviço Social brasileiro ${ }^{4}$. É digno de nota, entre os anos 1982 e 1995, o processo de formação profissional, desencadeado pela, na época, ABESS (hoje ABEPPSS) e pelo CEDEPSS ${ }^{5}$, por meio de uma análise histórica da profissão, com ampla participação de docentes, discentes e profissionais de diversas áreas, e pela condução do processo de revisão curricular do Curso de Serviço Social, que culmina com a apresentação da "Proposta Básica para o Projeto de Formação Profissional" (CADERNOS ABESS, 1995).

Na década de 1990 discute-se a direção teórico-metodológica da formação profissional, seus objetivos, e seu conteúdo, assim como a função social dessa formação e consequente intervenção profissional no contexto de classe da sociedade brasileira. Nesse cenário, está inscrito o Processo de Renovação do Serviço Social, acima sinalizado, com suas várias vertentes de diferentes matrizes teóricas. Apesar de não ser hegemônica na realidade prática, a perspectiva teórica de inspiração marxista, que busca romper com o conservadorismo profissional com base em uma tradição funcionalista e assistencialista, irá orientar o debate da maioria das produções teóricas.

Na sequência, em 1993, surge o novo Código de Ética do Serviço Social, que reafirma o compromisso com valores e princípios colocados no horizonte de um projeto de superação da ordem burguesa. Esse código procura avançar em relação aos equívocos identificados no Código de 1986, que incorpora de forma mecânica um modelo crítico dialético na apreensão da realidade. Ainda, no Código de Ética de 1993, está presente a discussão do pluralismo teórico e político, que implica um debate sobre diferentes projetos societários que se articulam aos distintos projetos profissionais presentes na realidade prática da profissão (NETTO, 2006). 
Nessa mesma direção teórico e crítica, é emblemático o trabalho desenvolvido por Marilda Vilela Iamamoto (1992), em que ela aborda dilemas e falsos dilemas no Serviço Social, principalmente, no que concerne à prática social deste, que deveria ultrapassar o fatalismo e o messianismo profissional.

Parece notório que, nos anos 1990, registram-se inúmeras conquistas e avanços profissionais, com o aprofundamento de temáticas decisivas para o exercício profissional, tais como: (a) as determinações institucionais da prática; (b) a discussão sobre as políticas públicas sociais; (c) as considerações sobre os movimentos sociais; (d) o debate acerca da cidadania e dos direitos sociais; (e) a articulação entre as dimensões teórico-metodológicas, ético-políticas e técnico-operativas, na formação e no exercício profissional.

O avanço do Serviço Social brasileiro em termos de pesquisa e de pós-graduação acompanha o debate nacional sobre formação e exercício profissional, particularmente suscitado pela ABEPSS e conjunto CFESS/ $\mathrm{CRESS}^{6}$. A ABEPSS tem-se mantido como o espaço privilegiado de debate da formação profissional do Assistente Social. A tendência teórico-metodológica da formação orientada por essa entidade tem sido a ratificação da teoria marxiana e do método dialético como núcleo fundante da apreensão das manifestações da questão social, bem como da necessidade de respostas na prática profissional orientadas pelo método dialético e operacionalizadas nas metodologias (instrumentos e técnicas) que devem corresponder ao espaço sócioocupacional do Assistente Social. A atual direção impressa pela ABEPSS é legatária do Processo de Renovação do Serviço Social brasileiro, antes aludido.

Desse ponto de vista, a ABEPSS, ao reafirmar os valores fundamentais previstos no Código de Ética (liberdade e justiça social) articulando-os à defesa intransigente da democracia (tomada como valor éticopolítico central), continua a ratificar o Projeto Ético-político que vem orientando a categoria. Esses valores democráticos, ao mesmo tempo em que asseguram a liberdade e a justiça social, ultrapassam os valores da ordem burguesa, que impõem limitações ao desenvolvimento da cidadania, dos direitos e das garantias individuais (CONSELHO FEDERAL DE SERVIÇO SOCIAL, 2012).

Seguindo essa orientação teórico-metodológica da indissociável relação entre método e teoria, o Serviço Social brasileiro, orientado pelas diretrizes curriculares, busca formar Assistentes Sociais que, em primeiro lugar, apreendam a totalidade da vida social produzida materialmente e desenvolvam a necessária articulação entre as dimensões teórico-metodológica, ético-política e técnico-operativa e exercício profissional, orientada pela racionalidade dialética ${ }^{7}$ (GUERRA, 2012).

Nessa direção, a ABEPSS tem estimulado a participação de pesquisadores nos Grupos Temáticos de Pesquisa $(\mathrm{GTP})^{8}$ como forma de atualizar as tendências e buscar o estado da arte das diversas manifestações da questão social a fim de aprofundar os seus fundamentos. Estão, portanto, a serviço da formação profissional do assistente social. Os encontros de pesquisadores promovidos por essa entidade demonstram a defesa desta em relação ao Projeto Ético-Político do Serviço Social com a necessária leitura de realidade, diante da regressão de direitos sociais, políticos e civis na sociedade brasileira.

Por seu turno, o conjunto CFESS/CRESS, pela própria natureza de acompanhamento do exercício profissional, não só aponta e atualiza, com base na vida profissional do Assistente Social, os temas recentes dos debates, como também reatualiza temas antigos, reapresentados como manifestações da questão social ${ }^{9}$. Os documentos CFESS MANIFESTA expressam os "principais posicionamentos políticos do Conselho Federal sobre diversas temáticas ligadas ao trabalho de assistentes sociais" (CONSELHO FEDERAL DE SERVIÇO SOCIAL, 2016). Esses temas trabalhados pelo conjunto CFESS/CRESS demonstram a perspectiva de que a entidade mantém um posicionamento teórico crítico, atualizando, no processo histórico, as demandas sócio profissionais do Assistente Social.

$\mathrm{Na}$ atualidade, parece cada vez mais urgente retomar a "Proposta básica para o processo de formação profissional", de 1996, que sinalizava a necessidade de:

imprimir um novo tratamento a essas questões é admitir que, ao constituir-se como assistente social, o profissional é um sujeito social cuja condição atravessada por componentes objetivos originados da sua atuação de classe, pela sua subjetividade e, consequentemente, por todas as mudanças e processos que afetam o mundo do trabalho, no qual ele está incluído. Ou seja, a subalternidade, as formas de alienação que perpassam as esferas da vida social, a insegurança de trabalho etc. (...) Sendo o assistente social sujeito do trabalho, os resultados da ação passam necessariamente pelo universo de valores incorporados na trajetória do seu processo de socialização. Ou seja, na formação da sua subjetividade, o que exige da formação não somente uma dimensão informativa, mas formativa. Nesta última, defende-se a consideração de questões como as relações de gênero, etnia, valores, aspirações religiosas, expressões artísticas e culturais, além de outros componentes da ordem afetiva, emocional etc. (ABESS; CEDEPSS, 1996, p. 163). ${ }^{10}$ 
Diante do exposto, coloca-se, como um dos grandes desafios enfrentados pela categoria profissional, a articulação entre os pressupostos teóricos-metodológicos do Projeto Ético-Político do Serviço Social, a Formação Profissional em nível de Graduação e de Pós-graduação e os seus impactos nos espaços sócio ocupacionais do Assistente Social. Esses desafios estão postos para o PPGSS-UFPA, que orienta a formação acadêmica no sentido de responder às expressões da "questão social" na Região Amazônica permeada de enormes desigualdades sociais, econômicas, políticas e culturais.

Há 20 anos, o Programa de Pós-graduação em Serviço Social, da Universidade Federal do Pará, escreve sua história no cenário nacional da pós-graduação brasileira e expressa as particularidades de uma região amazônica marcada, principalmente, pelas assimetrias regionais em relação aos programas de pós-graduação de outras regiões do país. Nesse sentido, o PPGSS-UFPA caminha rumo à maturidade e ganha espaço no âmbito da pesquisa e produção de conhecimento no contexto nacional, por meio de movimentos contínuos que alternam momentos de permanência e mudança.

\section{Programa de Pós-graduação em Serviço Social da UFPA: temas de pesquisa e desafios na Amazônia}

Na década de 1990, o Programa de Pós-Graduação em Serviço Social/PPGSS, do Instituto de Ciências Sociais Aplicadas/ICSA, da Universidade Federal do Pará/UFPA, acompanhou a expansão dos programas de Pós-Graduação da área de Serviço Social. Instituído no ano de 1996, o curso de Mestrado Acadêmico em Serviço Social foi reconhecido pela Coordenação de Aperfeiçoamento de Pessoal de Nível Superior (CAPES) por meio da Resolução n 3166/CONSEP, de 03/05/2004 e homologado pela Portaria nº 2878/CNE, de 24/08/ $2005^{11}$. O Programa tem como principais objetivos fortalecer não só uma formação crítica, com fundamentação histórica, teórica e metodológica, capaz de interpretar e responder às expressões da "questão social" no contexto da Região Amazônica e suas particularidades, mas também o Serviço Social como área de conhecimento e intervenção na Região Norte do Brasil e na Amazônia.

Atualmente, o PPGSS-UFPA apresenta como área de

As pesquisas realizadas no âmbito PPGSS/UFPA também têm indicado a necessidade do avanço de estudos que contemplem a particularidade das expressões da questão social na Amazônia, lugar de alta exploração da natureza e do trabalho pelo capital, lugar de variados impactos gerados pelo processo de acumulação em uma região, cuja população inclui povos indígenas e comunidades tradicionais. concentração "Serviço Social, Trabalho e Políticas Sociais" e, como linhas de pesquisa, "Serviço Social e Trabalho na Amazônia" e "Serviço Social e Políticas Sociais na Amazônia". No Programa, identificam-se 05 (cinco) Grupos de Pesquisa cadastrados na Plataforma do CNPQ, a saber: Laboratório de Pesquisas e Práticas Sociais na Amazônia (LABPSAM); Grupo de Estudos e Pesquisas Trabalho, Estado e Sociedade na Amazônia (G-TESA); Grupo de Pesquisa Cidade, Habitação e Espaço Humano (GEP-CIHAB); Grupo de Estudos e Pesquisa em Serviço Social, Política Social e Formação Profissional (GEPSS) e Grupo de Pesquisa Trabalho, Direitos Humanos e Seguridade Social (TRADHUSS).

O corpo docente do PPGSS/UFPA é constituído de 11 (onze) membros (7 do quadro permanente, 3 do quadro de colaboradores e 1 visitante) com doutoramento em diferentes instituições/áreas do conhecimento (7 em Serviço Social, 1 em Sociologia, 2 em Ciências Socioambientais e 1 em Ciência Política). Como parte dos esforços de qualificação do Programa, do total de docentes permanentes, 5 (cinco) realizaram Estágio Pós-Doutoral, em instituições nacionais e estrangeiras ${ }^{12}$.

Nos últimos 20 anos, de 1996 a 2016, o PPGSS-UFPA formou 195 mestres em Serviço Social (11 dissertações produzidas, em média, a cada ano). Registra-se que a primeira dissertação de Mestrado em Serviço Social foi defendida em 1998, dois anos após a criação do curso. Ao longo de vinte anos de existência, a quantidade de dissertações defendidas revela uma reduzida evasão e um número expressivo de mestres em Serviço Social ${ }^{13}$ com potencial para a verticalização do processo de formação continuada em nível de doutoramento. Nessa direção, registra-se o envio a CAPES, em julho de 2015, da Proposta de Doutorado em Serviço Social, a qual foi aprovada no início de 2016. 
As 195 (cento e noventa e cinco) Dissertações de Mestrado no âmbito do PPGSS-UFPA ${ }^{14}$, defendidas no período de 1998 a 2016, encontram-se esquematizadas de acordo com as temáticas ${ }^{15}$ pesquisadas no Gráfico 1, a seguir:

\section{Gráfico 1 - Temas de Dissertações de Mestrado defendidas PPGSS/UFPA (1998-2016)}

\section{TEMAS DE DISSERTAÇÕES DE MESTRADO DEFENDIDAS - PPGSS/UFPA (1998-2016)}

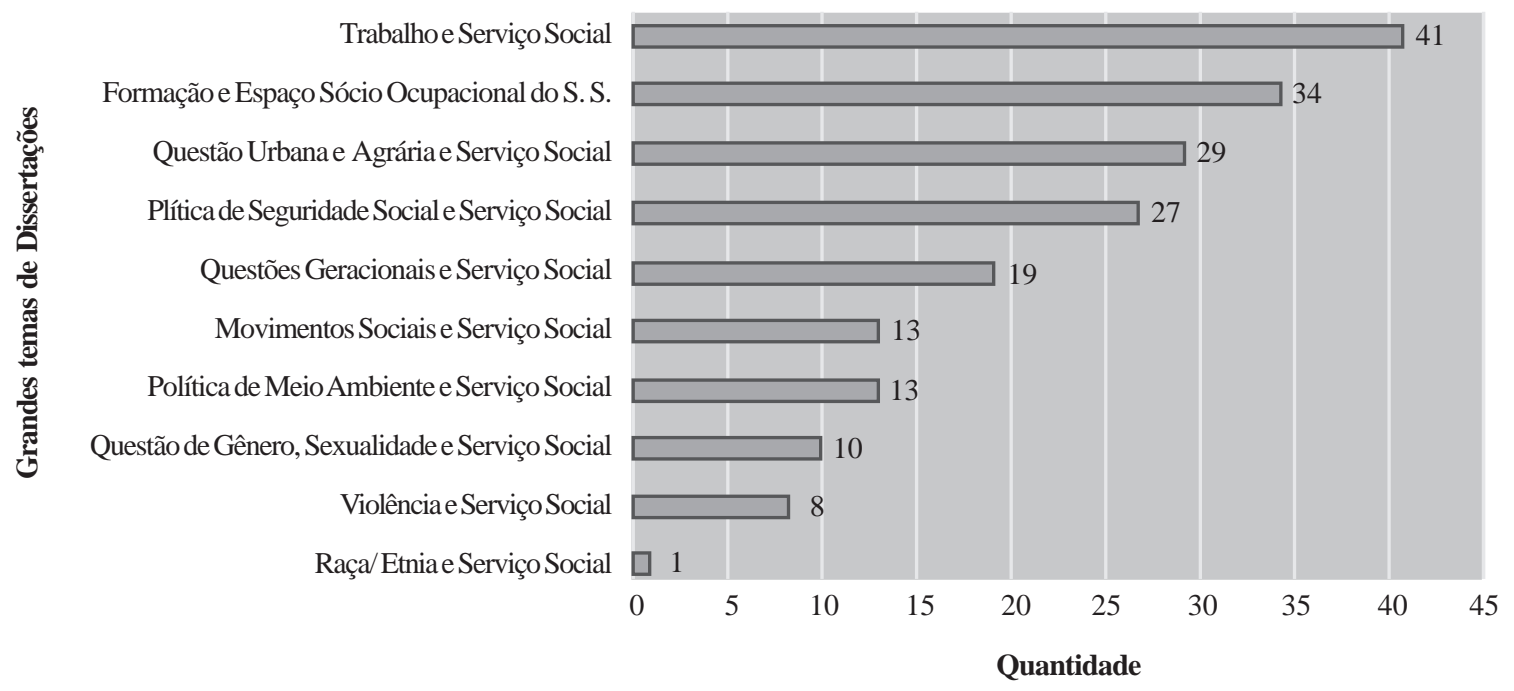

Fonte: Arquivo físico e em formato PDF de Dissertações de Mestrado defendidas no âmbito do PPGSS/UFPA, 2016.

A análise dos dados apresentados no Gráfico 1 demonstra que o Programa de Pós-graduação em Serviço Social da UFPA vem acompanhando o debate nacional acerca das diretrizes curriculares da ABEPSS, tendo em vista que o tema Trabalho foi o mais expressivo (41 dissertações) dentre os temas pesquisados nas dissertações. O levantamento ratifica a centralidade do trabalho como categoria fundante da profissão, a qual é requisitada para inserção, em sua grande maioria, nas políticas sociais públicas, cuja matéria-prima são as expressões da questão social, determinada pela luta de classes, pela exploração do trabalho e pelo capital.

É importante registrar que os demais temas expressos no Gráfico 1, também objetos de pesquisa das dissertações de Mestrado em Serviço Social da UFPA - Trabalho (41); Formação e espaço sócio profissional do Serviço Social (34); Questão Urbana e Agrária (29); Política de Seguridade Social (27); Questões Geracionais (19); Movimentos Sociais (13); Política de Meio Ambiente (13); Questão de Gênero e Sexualidades (10); Violência (08); Raça e Etnia (1), bem como outros discutidos pelo CFESS, conforme indicado na nota de rodapé número 9, estão articulados aos GTP da ABEPSS (nota de rodapé número 7).

Registra-se, ainda, que essas temáticas evidenciadas no levantamento das dissertações de Mestrado do PPGSS-UFPA também se articulam aos temas registrados nos Diretórios dos Grupos de pesquisa certificados na plataforma do CNPq, vinculados à área do Serviço Social. De um total de 264 (duzentos e sessenta e quatro) grupos certificados nessa plataforma, 50 (cinquenta) abordam o tema Trabalho, seguindo-se os temas: Políticas Públicas (34); Política Social (32); Cidadania, Democracia, Sociedade Civil, Controle Social (29); Direitos Humanos e Sociais (23); Movimentos Sociais, Lutas e Práticas Sociais (20); Gênero (18); Saúde (17); Questão Social (16); Fundamentos, formação e trabalho profissional (16); Questões Agrária, urbana e ambiental (15); Estado (15); Cultura (11); Família (10) e Estudos marxistas (10) ${ }^{16}$.

Passados 20 anos de formação profissional em Serviço Social, em nível de Mestrado, o PPGSS-UFPA aponta novos desafios, desta vez com a aprovação do Curso de Doutorado em Serviço Social. Relativamente à formação de pesquisadores na Amazônia, parece fundamental a continuidade do estudo dos fundamentos do Serviço Social, no sentido de apreender os elementos universais das requisições profissionais dessa área e as respostas efetivadas no campo interventivo, com a necessária articulação entre as dimensões teóricometodológicas, ético-políticas e técnico-operativas ${ }^{17}$.

As pesquisas realizadas no âmbito PPGSS/UFPA também têm indicado a necessidade do avanço de estudos que contemplem a particularidade das expressões da questão social na Amazônia, lugar de alta explo- 
ração da natureza e do trabalho pelo capital, lugar de variados impactos gerados pelo processo de acumulação em uma região, cuja população inclui povos indígenas e comunidades tradicionais ${ }^{18}$. Nesse sentido, parece um desafio importante evidenciar, na pesquisa, que a abundância de recursos naturais presentes na Amazônia permite a exploração do trabalho e da natureza nos mais variados espaços, o que resulta em expressões das questões agrária, urbana e ambiental, que, mesmo vistas em totalidade, podem ser apreendidas em seus elementos singulares e apanhadas na particularidade histórica.

Marx (2013, p. 667-668) afirma que: “A acumulação é a conquista do mundo da riqueza social. Juntamente com a massa de material humano explorado, ela amplia o domínio direto e indireto do capitalista”. No caso da Amazônia, as empresas capitalistas, com o aporte do Estado (SANTANA, 2012), o qual produz a infraestrutura física e social para as diversas frações de classe dominante (setor madeireiro, agronegócio/soja, óleo de palma, agropecuária, pesca, mineração, produção de megawatts pela construção de hidroelétricas, setor do mercado imobiliário, setor de turismo, setor financeiro), avançam sobre todos os espaços possíveis de produção do lucro, devastando florestas, rios, terras e espaços urbanos.

Como consequência, ocorre um processo de remoção de moradores da cidade, de indígenas, ribeirinhos e quilombolas, com retirada de pessoas com vistas à construção de projetos urbanos que embelezam as cidades para serem consumidas por quem pode pagar por elas, tendo como resultado uma verdadeira tragédia social com uma mudança compulsória de vida: modificação da produção de camponeses/agricultores familiares, avanço da monocultura mediante o discurso da modernização rural; migração de camponeses ao assalariamento nas lavouras de monocultura. Esses temas parecem indicar caminhos de pesquisa e prática profissional inseridos no âmbito do Programa de Pós-Graduação em Serviço Social da UFPA.

\section{Considerações finais}

A recuperação histórica dos 20 anos de existência do PPGSS-UFPA, especialmente por meio do levantamento e da sistematização dos temas de pesquisa das dissertações defendidas, infere que a produção acadêmica na área do Serviço Social da Universidade Federal do Pará, bem como na do Serviço Social brasileiro, vem percorrendo um caminho que se propõe a investigar: (a) os temas referentes às frações de classe dominadas (cf. POULANTZAS, 1980), notadamente os atinentes à exploração do trabalho que abordam a questão social e reatualizam as suas manifestações; (b) a luta por direitos (políticas públicas, política social, cidadania, democracia); (c) a organização política (movimentos sociais, lutas e práticas sociais); (d) o campo das opressões (especialmente gênero); (e) as questões agrária, urbana e ambiental, dentre outras. Os temas investigados demonstram, nesse sentido, que a profissão vem ampliando as pesquisas mediadas pelo exercício profissional do Assistente Social.

Nesse sentido, parece importante ratificar, no caminho da pesquisa científica do PPGSS-UFPA, a racionalidade dialética (ou a ortodoxia do método dialético nos termos de Lukács, 1974), com vistas a garantir a centralidade da análise da totalidade da vida social, que sugere, como desafio na pesquisa, a articulação dos elementos singulares e universais das variadas expressões da questão social, arrancadas da sua particularidade histórica. No caso da Amazônia, a necessária articulação com essa particularidade indica a ampliação de estudos que incorporem os temas atinentes às questões urbana, agrária e ambiental, como forma de apreender rebatimentos sociais e econômicos na vida social de trabalhadores urbanos, povos indígenas e comunidades tradicionais.

A pesquisa na Amazônia deverá continuar a cumprir o seu papel: interpretar, com rigor acadêmico, as expressões da questão social na Região como forma de contribuir para a proposição de políticas públicas voltadas às particularidades da vida social, bem como para as resistências e lutas políticas.

\section{Referências}

ASSOCIAÇÃO BRASILEIRA DE ENSINO EM SERVIÇO SOCIAL; CENTRO DE EDUCAÇÃO E PESQUISA EM POLÍTICAS SOCIAIS. Proposta básica para o Projeto de Formação Profissional. Revista Serviço Social \& Sociedade, São Paulo, n. 50, p. 143-171, 1996. ASSOCIAÇÃO BRASILEIRA DE ENSINO E PESQUISA EM SERVIÇO SOCIAL. Contribuição da ABEPSS para o fortalecimento dos Programas de Pós-Graduação em Serviço Social no Brasil (Gestão 2013 a 2014). Novembro de 2015. Disponível em: <http:// www.abepss.org.br/arquivos/anexos/contribuicao-da-abepss-para-o-fortalecimento-dos-programas-de-pos-revisto201703241351072223440.pdf>. Acesso em: 10 set. 2016.

CADERNOS ABESS. São Paulo: Cortez, n. 3, 1995.

CONSELHO FEDERAL DE SERVIÇO SOCIAL. Código de Ética do/a Assistente Social. Brasília: CFESS, 2012.

. Manifesta. Disponível em: <http://www.cfess.org.br/visualizar/manifesta>. Acesso em: 10 set. 2016.

. O CFESS. Disponível em: <http://www.cfess.org.br/visualizar/menu/local/o-cfess〉. Acesso em: 28 fev. 2017.

R. Katál., Florianópolis, v. 20, n. 2, p. 216-224, maio/ago. 2017 ISSN 1982-0259 
CONSELHO NACIONAL DE DESENVOLVIMENTO CIENTÍFICO E TECNOLÓGICO (CNPq), Diretórios dos Grupos de Pesquisa no Brasil. Disponível em: 〈http://lattes.cnpq.br/web/dgp>. Acesso em: 10 set. 2016.

FALEIROS, V. P. Confrontos teóricos do movimento de Reconceituação do Serviço Social na América Latina. Serviço Social \& Sociedade, ano 8, n. 24, p. 49-60, ago. 1987.

GUERRA, Y. A dimensão técnico-operativa do exercício profissional. In: SANTOS, C. M.; BACKX, S.; GUERRA, Y. (Orgs.). A dimensão técnico-operativa no Serviço Social: desafios contemporâneos. Juiz de Fora: Editora UFJF, 2012. p. 40-67.

IAMAMOTO, M. V.; CARVALHO, R. Relações Sociais e Serviço Social no Brasil: Esboço de uma Interpretação Teórico-Metodológica. São Paulo: CELATS/Cortez, 1988.

IAMAMOTO, M. V. Renovação e Conservadorismo no Serviço Social. São Paulo: Cortez, 1992.

LUKÁCS, G. O que é o marxismo ortodoxo? In: ___. História e consciência de classe. Porto: Escorpião, 1974. p. 63-104.

MARX, K. O capital: crítica da economia política. Livro 1. São Paulo: Boitempo, 2013.

NASCIMENTO, N. S. F.; BELO, P. S. Acumulação de capital e sociedades de economia natural na Amazônia: notas para o debate. Argumentum, Vitória (ES), v. 4, n.2, p. 225-236, jul./dez. 2012.

NETTO, J. P. Capitalismo Monopolista e Serviço Social. São Paulo: Cortez, 1996.

. Método y teoría en las diferentes matrices del Servicio Social. In: BORGIANNI, E.; MONTAÑO, C. (Orgs.). Metodologia y

Servicio Social. São Paulo: Cortez, 2000. p. 51-93.

. Ditadura e Serviço Social. São Paulo: Cortez, 2001.

. A construção do Projeto Ético-Político do Serviço Social. In: Serviço Social e Saúde. Formação e trabalho profissional. São Paulo: Cortez, 2006.

POULANTZAS, N. O Estado, o poder e o socialismo. Rio de Janeiro: Graal, 1980.

SANTOS, L. L. Textos de Serviço Social. São Paulo: Cortez, 1987.

SANTANA, J. V. Banco Interamericano de Desarrollo: significado del financiamiento y modelo de gestión de ciudades. Razón y Revolución, v. 23, p. 113-127, 2012.

UNIVERSIDADE FEDERAL DO PARÁ. Programa de Pós-Graduação em Serviço Social. Relatórios do Programa de Pós-Graduação em Serviço Social referentes ao período 2013-2016. Belém: UFPA, 2016.

\section{Notas}

1 Consideram-se vinte anos, pois o PPGSS-UFPA foi instituído em 1996. O levantamento realizado corresponde, porém, ao período de 1998 a 2016, uma vez que as defesas das dissertações iniciaram-se dois anos após o início do Curso de Mestrado.

2 Para atualização dos dados sobre a Pós-Graduação do Serviço Social Brasileiro, consultar o documento da ABEPSS (2015).

3 Sobre aspectos teóricos e históricos desse Movimento, consultar Faleiros (1987). Ressalta-se no Brasil, na década de 1970, a experiência do Método Belo Horizonte, desenvolvido em Minas Gerais por teóricos que questionavam objeto, objetivos e metodologia do Serviço Social tradicional. A esse respeito, cf. Santos (1987).

4 Em relação ao Processo de Renovação do Serviço Social brasileiro, consultar Netto (2001).

5 Associação Brasileira de Escolas de Serviço Social e Centro de Documentação e Pesquisa em Políticas Sociais e Serviço Social.

6 O Conselho Federal de Serviço Social (CFESS) é uma autarquia pública federal, cuja atribuição é orientar, disciplinar, normatizar, fiscalizar e defender o exercício profissional do/a assistente social no Brasil, em conjunto com os Conselhos Regionais de Serviço Social (CRESS)(CONSELHO FEDERAL DE SERVIÇO SOCIAL, 2017).

7 Racionalidade dialética, que exige a escolha do método de investigação. Nos dizeres de Netto (2000, p. 71, tradução nossa, grifo no original), “o método é uma relação necessária entre o sujeito que investiga e o objeto investigado. Quando digo necessária, quero usar toda a força do termo; é uma relação necessária na medida em que, para abordar um fenômeno determinado, e abordá-lo em sua verdade constituinte (porque a verdade dos fenômenos não está dada, é uma verdade que se constrói na história dos fenômenos), apenas uma perspectiva metodológicaé adequada. O método é como que a equação da razão constituinte entre o sujeito e o objeto".

8 Os GTPdaABEPSS são: 1. Trabalho, Questão Social e Serviço Social; 2. Política Social e Serviço Social; 3. Serviço Social: Fundamentos, Formação e Trabalho Profissional; 4. Movimentos Sociais e Serviço Social; 5. Questões Agrária, Urbana, Ambiental e Serviço Social; 6. Serviço Social, Relações de Exploração/Opressão de Gênero, Raça/Etnia, Geração, Sexualidades; 7. Ética, Direitos Humanos e Serviço Social.

9 Registram-se alguns temas debatidos pelo CFESS e publicados no documento CFESS MANIFESTA: Estado Laico; Saúde; Retirada das tropas brasileiras no Haiti; Serviço Social e diversidade trans; Dia internacional do trabalhador/trabalhadora; Análise de conjuntura; Questão da mulher; Consciência negra; Educação; Combate ao trabalho infantil; Grandes eventos esportivos e direito à cidade; Contra a Empresa Brasileira de Serviços Hospitalares; Juventude brasileira; Assistência Social; Saúde indígena; Contra o abuso e tráfico ilícito de drogas; Combate à exploração sexual de crianças e adolescentes; Trabalho doméstico; Luta indígena;Visibilidade trans; Direitos Humanos; Pessoas com deficiência; Organização sindical; Exploração sexual e tráfico de mulheres e crianças; Crianças e adolescentes; Meio ambiente; Luta antimanicomial; Luta camponesa e luta pela reforma agrária; População de rua; Pessoa idosa; Questão urbana; Saúde Mental; Descriminalização e legalização do aborto; Luta contra a homofobia/Orgulho LGBT; Relaç̃̃es de trabalho; Seguridade Social; Democratização dos meios de comunicação; Fim da criminalização dos movimentos sociais; OServiço Social no Campo Sociojurídico. 
10 O artigo intitulado "Proposta básica para o Projeto de Formação Profissional" refere-se ao "Documento apresentado na XXIX Convenção Nacional daABESS, realizada em Recife-PE, em novembro de 1995, para subsidiar as discussões sobre a revisão curricular. A responsabilidade do documentoé daABESS/CEDEPSS que, para sua elaboração, contou com a participação das seguintes consultoras: Ana Elizabete Mota (UFPE), Isabel Cristina Cardoso (UERJ), Marilda Iamamoto e Nobuco Kameyama(UFRJ), Maria Lúcia Barroco e Maria Rosangela Batistoni (PUC-SP)" (ABESS; CEDEPSS, 1996, p. 143).

11 O curso de Mestrado Acadêmico em Serviço Social do PPGSS/UFPAe o curso de Mestrado Acadêmico em Serviço Social e Sustentabilidade na Amazônia, da Universidade Federal do Amazonas (UFAM), constituem-se os únicos cursos de mestrado desta área do conhecimento em toda a Região Norte do Brasil.

12 Do ponto de vista histórico, vale registrar que, no ano 2000, a UFPA estabeleceu um convênio de cooperação com a Universidade Federal do Rio de Janeiro (UFRJ), ocasião em que foram aprovados no curso de Doutorado da Escola de Serviço Social da UFRJ seis docentes oriundos da Faculdade de Serviço Social da UFPA. A partir de 2006, quatro desses doutores somaram-se ao corpo docente já existente no PPGSS/UFPA, e vêm agregando suas pesquisas e atividades de ensino e orientação ao Programa. Nesse espaço de tempo, o Programa de Pós-Graduação formou um quadro próprio e estável que lhe proporcionou organicidade (UNIVERSIDADE FEDERAL DO PARÁ, 2016).

13 O acompanhamento de egressos realizado pelo PPGSS revela a inserção destes na condição de docentes do ensino superior (em instituições federais e ensino privado), bem como na condição de técnicos de nível superior (UNIVERSIDADE FEDERAL DO PARÁ, 2016).

14 As dissertações de Mestrado têm como locus de pesquisa municípios paraenses (principalmente Belém) e outros estados da Amazônia Legal (Amapá, Maranhão e Tocantins).

15 A partir de 2013, o PPGSS, com base nos documentos físicos e arquivos digitalizados, empreendeu esforços no sentido de catalogar todas as dissertações de Mestrado defendidas no Programa a fim de atualizar sua página na internet. Esse material serviu de base para o levantamento de dados apresentados no Gráfico 1.

16 Levantamento realizado na página do CNPq/Diretórios dos Grupos de Pesquisa no Brasil. Dos 264 Diretórios certificados, optou-se por apresentar, nesse texto, os temas que aparecem com frequência igual ou superior a 10.

17 Em termos históricos, o Programa de Pós-Graduação em Serviço Social da UFPA vem desenvolvendo suas atividades de modo a responder às orientações da CAPES. O objetivo é garantir uma formação qualificada de pesquisadores. Destaca-se, nesse processo, a efetivação de projetos de pesquisa dos docentes cujos temas têm por base as expressões da questão social na Amazônia, empreendendo-se um esforço para que os temas de pesquisa dos discentes se articulem aos referidos projetos.

18 Segundo Nascimento e Belo (2012,p. 226), a RegiãoAmazônica sobressai pela abundância de recursos naturais (com destaque para os minérios), os quais têm sido objeto de exploração por empresas multinacionais, mediante a implantação de grandes projetos na Amazônia. Desde o período de sua colonização, a Região foi inserida de forma subordinada ao mercado mundial capitalista, por conta, especialmente, da exploração dos referidos recursos. Segundo as autoras: “Os processos sociais, econômicos e ambientais resultantes da implantação desses empreendimentos do capital, e de grande capital, naAmazônia, têm produzido processos sociais, econômicos e ambientais que afetam as condições de vida de milhares de amazônidas, sejam eles nativos ou migrantes".

\section{Adriana de Azevedo Mathis}

adriana.azevedo.mathis@gmail.com

Doutorado em Serviço Social pela Universidade Federal do Rio de Janeiro (UFRJ)

Professora da Faculdade e do Programa de Pós-Graduação em Serviço Social (PPGSS) da Universidade Federal do Pará (UFPA)

\section{Joana Valente Santana}

joanavalente@ufpa.br

Doutorado em Serviço Social pela Universidade Federal do Rio de Janeiro (UFRJ)

Professora da Faculdade e do Programa de Pós-Graduação em Serviço Social (PPGSS) da Universidade Federal do Pará (UFPA)

\section{Max Nazareno Miranda da Silva}

maxmiranda0610@hotmail.com

Graduando do Curso de Graduação em Serviço Social pela Universidade Federal do Pará (UFPA)

\section{Jaqueline do Nascimento Cruz}

jaque.cruz97@gmail.com

Graduanda do Curso de Graduação em Serviço Social pela Universidade Federal do Pará (UFPA) 


\section{UFPA}

Rua Augusto Corrêa, 01 - Guamá

Belém - Pará - Brasil

CEP: 66.075-110 